\title{
History of Psychology in Islamic Republic of Iran
}

\author{
Mahdi Anbari, Diana - Lea Baranovich , Muhammad Azahar Zailaini
}

\begin{abstract}
: this survey carried out aims to achieve an overall view about history of psychology in iran. The main keyword to find resources and articles was "psychology in iran" but other related concepts in the field of mental health was used such as psychiatric, counseling and mental health disorder. Furthermore, some information was referenced as iranian, sources such as interview of government and academic officials, also reliable and official websites. The final objective in this study was to extract advantages and disadvantages concerning mental health sciences, specially psychology in iran. Despite many efforts in progress in psychology and other related mental health fields, iran is facing various issues centered around people in general, culture and religious issues in mental health services, parallelism among responsible organizations and a wide distance between university mental health programs and the needs of people. Considering iran's current situation in terms of psychology and mental health services, the objectives, concepts, courses, contents, academic resources, teaching methods, professors' knowledge, treatment procedures and approaches, mental health fields and methods, along with past research should be reviewed and elaborated upon in order for iran to meet the high global criteria for mental health.
\end{abstract}

Key words: Psychology, Psychiatric, Counseling, Mental Health, History of Iran

\section{INTRODUCTION}

The Islamic Republic of Iran, formerly known to the Western world as Persia until 1935, is a country with a proud and ancient history[1]. The Islamic Republic of Iran has an area over $1648000 \mathrm{~km}^{2}$; it is located in the Middle East and has a population of more than 80 million[2]. The dominant religion Iranian's population is Shia Muslim via $89 \%$, and Sunni Muslim via 9[3] .In Iran, psychology as a branch of philosophy has a long history, but psychology as a scientific discipline does not have such a long history. Almost all Iranian philosophers, such as Farabi, Ghazali, and Avicenna, have paid attention to psychological issues, such as perception, sensation, mood, memory, and cognition from a philosophical viewpoint[4].

Revised Manuscript Received on November 15, 2019.

Mahdi Anbari, Department of Educational Psychology and Counseling, Faculty of Education, University of Malaya.

Diana - Lea Baranovich, Department of Educational Psychology and Counseling, Faculty of Education, University of Malaya.

Muhammad Azahar Zailaini, Faculty of Education; Department of Language and Literacy Education, University of Malaya, Kuala Lumpur, Malaysia.
Psychology in Iran as an academic major began in 1937 when the medical school of Tehran began teaching methods of psychiatry to its students[5]. This process continued until 1963 when that first psychology department was established at the University of Tehran. After the revolution in 1979, the country faced many serious matters, such as people immigrating from the rural areas to the big cities. This allowed for more access to drugs, specially opium, Furthermore, this lead to the conflict between old and new cultures, as well as the Iran-Iraq war. [1] Fortunately, general health improved in the country. These achievements were possible because of the primary health care (PHC) system. In addition, new activities into PHC system as the National Programme of Mental Health (NPMH) were integrated in 1986. This formed a much better outlook for mental health in Iran[6] .Perhaps before establishing the Psychology and Counseling Organization of Iran by the parliament in 2003, the biggest threat to this discipline was the practice of unprofessional people[7]. However, even after the establishment of this organization, the health supreme system has not been able to integrate all organizations related to mental health and there continues to be many conflicts among the mental health professions.This study proports to investigate the psychology, as a mental health profession in Iran as a multidimensional subject. Indeed, both psychology and psychiatry are considered similar subjects and sometimes the mental health field uses them synonymously. This overview will include the most important dimensions of psychology that have been studied in Iran to date. These dimensions include background of the academic fields, number of universities and students, and research.

\section{PSYCHOLOGY BACKGROUND IN IRAN}

The origin of counselling and psychotherapy in Iran follow back to Zoroaster's teachings in Avesta (Zoroaster's book). After the advent of Islam was extended in Iran, Muslim scientists did research in all fields based on the teachings of Islam as told in the Quran, especially in human science[3]. The teaching of philosophy and education started after establishing Tehran University by Dr. Siyasi, who is known as the father of psychology in Iran. In 1935, the first psychological laboratory was established and the first Persian textbook of psychology, Science of Mind, was published in 1938. Eventually, the first psychology department was established in 1963. Since 1954, mental health in Iran has supervised by Professor Krauz, the envoy of the World Health Organization (WHO), sent a comprehensive and regrettable report about the situation of mental patients to WHO in 1954 , and, since that time, WHO has 
paid some attention to the mental health problems in Iran.Psychology in Iran has been really developed after some activities which include; a radio program in 1955, devoting $2,000,000 \$$ to improve mental health, establishing a school for psychiatric nursing in 1960, a school for mental retardation children in 1962, funding was attained for the first Psychological Association of Iran by a group of psychologists in 1968, the first Iranian journal of psychology was published sin 1970, and the Masters of Science (MS) degree in clinical psychology was established in Roozbeh Hospital in 1971[5]. After the revolution, the MS degree and Doctorate of Philosophy (Ph.D.) degree in psychology were started again in 1985 and 1995 respectively[4]. The mental health services in Iran were divided to four stages. In the first stage (before 1940), he country had serious problems in mental health and there were minor facilities. The second stage (1940-1960) continued with establishing medical school, academic hospitals and the development of psychiatric departments. The third stage (1960-1979) included doing an epidemiological research projects, establishing new psychiatric institutions and starting psychiatric nursing course general training throughout the country. The fourth stage (1986-1998) began to integrate National Programme of Mental Health (NPMH) with Primary Health System (PHC)[6].The main components to improve the current situation at that time were promotion, prevention, treatment and rehabilitation in whole of country from 1986 to 1998. Based on these activities, pilot studies in Shahr-e-Kord and Shahreza, have shown significantly increased knowledge of specialists. Improving knowledge and attitude of health staffs through workshops and seminars and public awareness about mental health through the mass media. For example, seeking from traditional healers shifted from $42 \%$ in 1990 to $14 \%$ in 1998 (8).

\section{EDUCATION AND APPROACHES}

The twenty first century can be called a century of tremendous changes in social, economic and cultural fields. Accordingly, the most important goal of education in this century should be to nurture learners that are ready to face the changing society and the complexity of the over whelming abundance of information via the internet. Studies by Shabani (1995) and Yazdanpanah (2007) have shown that poor intellectual performance of students in Iran is not scarce[9]. Currently 19 universities in Iran teach psychology in their undergraduate programs. The Bachelor of Science (BS) degree in psychology is awarded after 4 years of study. Courses follow the credit-hour and semester system and psychology programs leading to the BS in psychology require 130-135 credit hours of study to be completed over eight semesters. Credit hours refer to the number of hours each course meets per week during a semester. According to A. Alipour (2006) there were about 34,000 psychology students at the BS level in Iran[4] whereas, based on official declaration Dr Fathi Ashtiani in Mehr News Agency in 2014, the number of students in bachelor of psychology is about 222,000[10]. These students study in four main fields of psychology: general psychology, clinical psychology, psychology and education of exceptional children, and industrial/organizational psychology. The majority of students are studying in general psychology programs. Students can also continue their studies in psychology towards the Masters of Science (MS) and Doctorate of Philosophy $(\mathrm{PhD})$ degree programs. There has been considerable growth in the number of universities in the regional areas of Iran in recent years, and this trend has coincided with the development of distance-education methods[4]. Psychology and education are inter-related disciplines in Iran. Over one half of the universities offering psychology degrees have faculties of psychology and education, rather than a faculty of psychology. In other Iranian universities, psychology departments are part of humanities faculties. Payame Noor University and Islamic Azad University are expansive universities that have numerous branches throughout the country[4].Currently, psychology has been extended by a variety of psychology fields in Iranian universities. According to Iranian Psychological Association more than 10 fields are teaching now that include General, Clinical, Industrial, Exceptional Children, Counselling, Islamic, Family, Psychometric, Clinical Children, Educational, School, Health, and Neuroscience[11].There are many similarities between Iran and developed countries such as United States in terms of psychology courses, approaches and content. But one of the most important differences between Iranian universities and foreign universities is Iranians weakness in speaking, reading and writing in the English language. In a research project which investigated four English language skills among Iranian students about the content material and class activities in ESP (English for specific purposes), only 26.26 percent of the students agreed with this item as a mandatory course. Furthermore, $69.1 \%$ of the students believed that ESP courses will be useful in their future lives; however, not in the current course[12].Although the discipline of psychology is alive and well in Iran, it takes a somewhat different form than the one constructed in the West. For example, Iranian psychology departments are branches of education faculties, not of arts or science faculties. Iranian university students can pursue a B.A in clinical psychology as well as general psychology. Most Iranian psychology professors, for example, think their students are lazy, most Iranian students think their psychology professors are boring, and all students hate their courses in statistics[13].In recent decades, and while we are passing the first generation of approaches to psychotherapy, the development of approaches and maximization of the effectiveness of these approaches has drawn specialists and psychotherapists' attention to the point that the number of psychological approaches and consultation to treatment has reached 400. Even though all approaches share the same goal, and consequentially share the same premises, they also have differences. These differences are caused based on the theory from which they were formed and also, naturally, the subject of the treatment they looking forward to[14].The dominant psychotherapeutic theories and methods in Iran are those borrowed from western countries, mainly the USA. The most used of these techniques are behaviour therapy, cognitive therapy, cognitive behavioural therapy and analytic 
therapy[15].Nowadays in Iran, main theories presented in introductory courses include classical and operant conditioning, social learning theory, other learning theories, cognitive theories, personality theories, and social psychology theory. Unfortunately in other related disciplines and higher level degree programs, there is no differences in the approaches thought [4].In the analytical-descriptive research conducted in Shiraz and Tehran during 2014-2016 survaed psychiatrists and psychologists as to what theoretical orientations they were using when working inn their clinics and/or their private office. This study used an instrument and a research question that investigated the following theoretical orientations: Adlerian, Gestalt, cognitdive, behavioral, and integrated or others. CBT and integrated approaches were the most popular ones and Adlerian and Gestalt were the les popular approaches. Psychiatrists and psychologists both preferred CBT as their first choice among psychotherapy approaches[14].After the revolution in 1979, some psychologists have shown innovations in psychotherapy based on traditional concepts and techniques, used in ancient times in Iran, which include; Story therapy, Poetry therapy, Selflessness, Meditation, Serenity, Hope and Forgiveness that any of these approaches not common now[15].

\section{RESEARCH}

Research in mental health disorders is urgently needed in developing countries because of the imbalance between the burden of mental disorders and the resources for managing them in these countries. In addition, there is a large gap between the research information that is needed and what is currently available. Therefore, a prerequisite to strategic research planning and policy-making in any country should be the knowledge of the status of research in that country. This is especially important for developing countries that have limited resources and capacity for research[17].The trend of publications showed an upwards trajectory both in local as well as international publications, especially in the last 5 years. This is paralleled by the rise in the Islamic Republic of Iran's production of science research papers over the last decade. A study on those publications indexed in ISI revealed that the production rose from $0.03 \%$ of the world's scientific output in 1991 to $0.29 \%$ in 2003 , which indicates about a 10 -fold increase in less than 15 years[18].The Islamic Republic of Iran has substantially increased its presence in world science in recent years. According to papers indexed by the Institute for Scientific Information (ISI), the Islamic Republic of Iran's output in science, although still comparatively small, more than tripled from 1996 to 2002[18].From the total of 3113 articles published in the 30 -year period, $680(21.8 \%)$ appeared in foreign journals and the remainder were published in local journals that are not indexed in international databases. In $14.5 \%$ of the articles there was collaboration among professionals in mental health and other disciplines, and in only $2.3 \%$ of the articles was there any international collaboration among the authors. In 875 papers $(28.1 \%)$ there was a single author, and the average number of authors was 2.44 for all papers[17].Among general research areas, psychology and clinical research had the largest share, with 1637 (52.6\%) and 968 articles (31.1\%), respectively. Neuroscience, epidemiology and health services research articles were the other major areas with 445 (14.3\%), $325(10.4 \%)$, and 97 articles $(3.1 \%)$ respectively[17].Another important finding of the study was the absence of any reference to the funding sources in more than $90 \%$ of the articles. The most likely reason may be lack of acknowledgement by the researchers despite the presence of financial support. None of the articles reported received support from industry. Funding by industries is a neglected area in developing countries, not only in mental health but also in most scientific and medical disciplines[19].During the new millennium, there were certain popular journals that most Iranian psychologists read and in which most Iranian psychological research is published. These include the Journal of Psychology (Quarterly Journal of the Psychological Association of Iran), Quarterly Journal of Andeesheh Va Raftar (A Journal of Psychiatry and Clinical Psychology), and the Journal of Psychology and Education (published by the faculty of psychology and education in Tehran University)[19].According to official declaration of Iranian Psychological Association, currently there are 12 especially journal in mental health disorders in academic and research institutes that consider just 9 of them are active now[11]. According to statistics, Iran produced 34,155 articles in 2012, which gained the country the world's 17th rank in science production and fixed its top position in the region, above Turkey. Scientific progress over the past few years was the result of the country's recent policies and programs to develop knowledge and facilitate researchers' access to the world's top academic resources. Iran has the world's fastest-growing scientific output, measured by the number of peer-reviewed papers published in international journals. In addition, Iran ranked first in scientific growth in the world in 2011. In 2000, the Islamic Republic of Iran ranked 53rd in the world in terms of highly cited medical articles but improved to the 23 rd rank in 2011. According to the Institute for Scientific Information (ISI), Iranian researchers and scientists published a total of 60,979 scientific articles in major international journals from 1999 to 2008[20].

\section{DISCUSSION}

This survey's aim was to achieve an overall view about history of psychology in Iran. Today, psychology and other similar disciplines have special criteria in terms of aims, definition, application, education and research. Psychology as a major is a new identity that seeks to integrate three different subjects in Iran, commitment to religion and Islamic philosophy, use of new and international methods and approaches, and meeting the present needs of Iranian people[23]. Although it seems the psychology in Iran has a spectacular view, there is irregularity among government, parliament, academic centers and professional associations[4]. First of all, according to N. Memaryan (2016), spiritual concepts, can have a positive impact on health services, education, research and practice in Iran and other same countries[22].

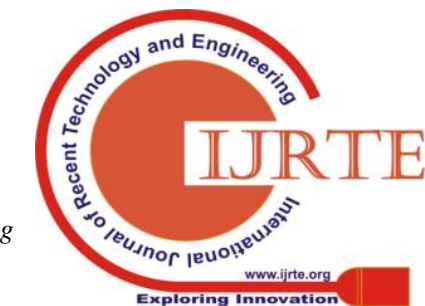




\section{History of Psychology in Islamic Republic of Iran}

However, most of the empirical studies conducted among Muslim countries have small sample sizes [21] and their interventions are not evidence-base[23]. The next subject is education and research. Although, there are many similarities between Iran and developed countries, one of the most important differences is weakness in English language as an international language[12]. This explains why students and professors are dissatisfied from ESP and there is less participation in scientific international societies by Iranian researchers[16]. Of course, current economic conditions and getting visa have added to researcher problems. According to A.Alipour (2006), there is a significant difference between professors and students in their attitudes and desires[4]. Furthermore, the main threat for psychology and counseling programs is the universities' reduction in the quality of the courses being offered. This is a result of not paying attention to modified curriculums. However, in terms of research, trends show a marked increase in the number of publications since 1995[17]. Also, Iran has ranked 17th in scientific publication according to Scopus database in 2012[20]. Despite Iran has many problems in psychological researches include; lack of database for research publications, limitation in data collection and sampling, and lack of funds and grants[17]. This is likely due to the fact that research is usually done by persons who do not have the necessary competencies. Physicians and psychiatrists who conduct research are more knowledgeable about research methodology as compared to psychologists. Furthermore, psychiatrists insist on pharmacotherapy more than psychotherapy. Just the opposite of fifth wave of psychology. The first and foremost method used by most practitioners of psychotherapy is CBT. Also, people seeking mental health services are more likely to be treated with psychotropic medicines because there is a visible result [14]. Therefore, most mental health clients and patients visit psychiatrists rather than clinical psychologists because only psychiatrists can write prescription and use of insurance coverage[16]. According to A. Mirabzade (2018) Iranian people do not differentiate between mental health difficulties and mental health disorders[24]. As a result, they need more information by educational organization and mass media for improving their life style.

\section{CONCLUSION}

In conclusion, psychology and mental health is receiving more awareness among the people of Iran; however, it takes on somewhat of a different form than the one constructed in the West. Iranian universities are weak in English language as an international language. The objectives of the psychology programs and courses, resources available, teaching methods and professors' knowledge should be reviewed and improved upon. Psychologists, psychiatrists and other mental health practitioners should move toward the use of the fifth psychology wave. The mass media should also place an importance of helping to spread the awareness of psychology and mental health as a means to improve the overall quality of life. Furthermore, the mental health sciences suffer from lack a database for their researches publication. Much of the mental health research in Iran is carried out by physicians who

have not had adequate schooling in, research methodology skills, and most of the locations chosen for data collection are chosen due to convivence. Researchers are usually not supported by industries and are faced with minimal financial resources. Because of the present economic conditions in Iran and the difficulties in obtaining visas, it is difficult for researchers to participate in scientific international societies. Finally, behind the political headlines of Iran, there remains a rich and diverse culture, full of well-educated, well-read, thoughtful, and hospitable people eager to be a part of the growing global community of psychologists and mental health professionals.

\section{REFERENCES}

1. P. E. Priester, "Mental Health Counseling in the Islamic Republic of Iran: A Marriage of Religion, Science, and Practice," Couns. Values, vol. 52, no. 3, pp. 253-264, 2008 .

2. SCI, "Statistical center of Iran," 2018. [Online]. Available: https://www.amar.org.ir/

3. E. By, R. O. Y. Moodley, U. W. E. P. Gielen, and R. Wu, HANDBOOK OF COUNSELING AND PSYCHOTHERAPY IN AN INTERNATIONAL CONTEXT EDITED BY ROY MOODLEY , UWE P . GIELEN , AND ROSA WU HANDBOOK OF COUNSELING AND PSYCHOTHERAPY IN AN. .

4. A. Alipour, "Teaching undergraduate psychology in the Islamic Republic of Iran," Int. J. Psychol., vol. 41, no. 1, pp. 35-41, 2006.

5. J. E. and M. D. Kermani, "Psychology in Iran," Br. Commun., pp. 949-952, 1966.

6. M. T. Yasamy et al., "Mental health in the Islamic Republic of Iran: Achievements and areas of need," Eastern Mediterranean Health Journal, vol. 7, no. 3. pp. 381-391, 2001.

7. A. Allahyari, "Reviewing the Opportunities and Threats to Psychology and Counseling in Iran," Neurosci. J. Shefaye Khatam, vol. 2, no. 3, p. 2014, 2014.

8. E. On, "MENTAL HEALTH SYSTEM IN THE ISLAMIC REPUBLIC OF IRAN," 2006

9. M. Sedaghat and S. Rahmani, "A review of approaches to teaching thinking: Appropriate approach for Iran education system," Procedia Soc. Behav. Sci., vol. 30, pp. 1037-1042, 2011.

10. M. news Agency, "The statistic of psychology students," 2014. [Online] Available: https://www.mehrnews.com/news/2349222

11. I. P. Association, "Iranian Psychological Association." [Online] Available: http://www.iranpa.org/.

12. F. Abiri, "Exploration of English Needs According to Teachers and Learners in the Psychology Major in Iranian Universities," Procedia Soc. Behav. Sci., vol. 70, pp. 821-826, 2013.

13. WARREN THORNGATE, "Psychology in Iran." [Online]. Available: https://www.psychologicalscience.org/observer/psychology-in-iran.

14. M. Mousavi, R. Alavinezhad, and M. Khazaei "Psychotherapy approaches of Iranian psychiatrists and psychologists," 2018.

15. Seed Shamloo, "Psychology in Iran," Tehran, Iran.

16. B. Ghobari and J. Bolhari, "The current state of medical psychology in Iran,” J. Clin. Psychol. Med. Settings, vol. 8, no. 1, pp. 39-43, 2001.

17. S. V. et al., "Analysis of mental health research in the Islamic Republic of Iran over 3 decades: A scientometric study," East. Mediterr. Heal. J., vol. 14, no. 5, pp. 1060-1069, 2008.

18. M. Moin, M. Mahmoudi, and N. Rezaei, "Scientific output of Iran at the threshold of the 21 st century," Scientometrics, vol. 62, no. 2, pp. 239-248, 2005

19. A. Okasha and E. Karam, "Mental health services and research in the Arab world," Acta Psychiatr. Scand., vol. 98, no. 5, pp. 406-413, 1998

20. "Editorial Iranian science shows world' s fastest growth : ranks 17 th in science production in 2012," vol. 5, no. 3, p. 2030, 2017.

21. H. Abu-Raiya and K. I. Pargament, "Empirically based psychology of Islam: Summary and critique of the literature," Ment. Heal. Relig. Cult., vol. 14, no. 2, pp. 93-115, 2011.

22. N. Memaryan, M. Rassouli, and M. Mehrabi, "Spirituality Concept by Health Professionals in Iran: A Qualitative Study," Evidence-based Complement. Altern. Med., vol. 2016, 2016. 
23. S. G. Symbiosis, N. Memaryan, Z. Ghaempanah, and R. Seddigh, "Spiritual interventions in Iran: A review article," 2017.

24. A. Mirabzadeh, M. Baradaran Eftekhari, K. Falahat, H. Sajjadi, M. Vameghi, and G. Ghaedamini Harouni, "Positive Mental Health from the perspective of Iranian society: A qualitative study," F1000Research, vol. 7, no. 0, p. 103, 2018 